\title{
Immunocytochemical Localization of Chromatin Regions UV-microirradiated in S Phase or Anaphase
}

\author{
Evidence for a Territorial Organization of Chromosomes during \\ Cell Cycle of Cultured Chinese Hamster Cells
}

\author{
LUC HENS, ${ }^{1,}{ }^{*}$ HELLA BAUMANN,${ }^{2}$ THOMAS CREMER, ${ }^{2}$ \\ AXEL SUTTER, ${ }^{2}$ JAN J. CORNELIS ${ }^{3}$ \\ and CHRISTOPH CRFMER ${ }^{4}$ \\ ${ }^{1}$ Laboratory of Human Genetics, Vrije Universiteit Brussel, B-1050 Brussels, Belgium, \\ ${ }^{2}$ Institute of Anthropology and Human Genetics, Universität Heidelberg, D-6900 \\ Heidelberg, Germany, ${ }^{3}$ Department of Molecular Biology, Université Libre \\ de Bruxelles, B-1640 Rhode-St.-Genèse, Belgium, and ${ }^{4}$ Institute of Human \\ Genetics and Anthropology, Universität Freiburg. \\ D-7800 Freiburg i. Br., Germany
}

\begin{abstract}
Chinese hamster cells (M3-1 line) in S phase were laser-UV-microirradiated $(\lambda, 257 \mathrm{~nm})$ at a small site of the nucleus. Cells were fixed either immediately thereafter or in subsequent stages of the cell cycle, including prophase and metaphase. The microirradiated chromatin was visualized by indirect immunofluorescence microscopy using antibodies specific for UV-irradiated DNA. During the whole post-incubation period (4-15 h) immunofluorescent labelling was restricted to a small part of the nucleus $(\bar{x}, 4.5 \%$ of the total nuclear area). In mitotic cells segments of a few chromosomes only were labelled. Following microirradiation of chromosome segments in anaphase, immunofluorescent labelling was observed over a small part of the resulting interphase nucleus. A territorial organization of interphase chromosomes, i.e. interphase chromosomes occupying distinct domains, has previously been demonstrated by our group for the nucleus of Chinese hamster cells in G1. Our present findings provide evidence that this organization pattern is maintained during the entire cell cycle.
\end{abstract}

Evidence has recently been provided for a highly ordered arrangement of centromeres in metaphase plates of certain plant species [1]. Non-random arrangements of chromosomes have also been shown to a certain extent in metaphase plates of several mammalian species including man $[2,3]$. These findings have shed new light on the question of an ordered arrangement of interphase chromosomes as well, a question which still appears largely unsettled [3-7]. Within this context it is important to know how the chromatin of individual chromosomes is distributed within the interphase nucleus at different stages of the cell cycle.

In 1885, Rabl [8] suggested a model which predicts that interphase chromosomes maintain their anaphase-telophase orientation and occupy distinct nuclear

* To whom offprint requests should be addressed. 


\section{Hens et al.}

domains or territories. Circumstantial evidence for this model has been provided at an early stage by Boveri $[9,10]$, but only recently methods have been developed to put Rabl's predictions to more rigorous tests [11-14]. Whereas a territorial organization has been demonstrated for interphase chromosomes of Chinese hamster cells in G1 [12, 15], direct evidence was still lacking for cells in S phase.

In the present experiments we have combined laser-UV-microirradiation of nuclei of the Chinese hamster cell line M3-1 [16], and an immunofluorescent staining technique using antibodies for UV-irradiated DNA [17, 18]. This method allows the detection of chromatin microirradiated at any stage of the cell cycle both immediately after irradiation and after different time intervals. A small part of the cell nucleus was microirradiated in $\mathrm{S}$ phase and microirradiated chromatin was identified at subsequent stages of the cell cycle, including prophase and metaphase. Alternatively, chromosomes were microirradiated in anaphase, and their arrangement was tested in the resulting interphase nucleus. Our results indicate that in Chinese hamster cells a territorial organization pattern of interphase chromosomes is maintained during the entire cell cycle.

\section{MATERIAL AND METHODS}

\section{Cell culture}

Chinese hamster cells of the M3-1 line [19] were used in the present experiments. These cells have a rapid, well-characterized growth (cycle duration of undisturbed cells $10.5 \mathrm{~h}, \mathrm{~S}$-phase duration $6.6 \mathrm{~h}$, G2M-phase duration $1.5 \mathrm{~h}$ [20]). Stock cultures were maintained in plastic Falcon flasks in Eagle minimum essential medium (MEM), supplemented with $10 \%$ fetal calf serum (FCS) and $1 \%$ nonessential amino acids (NEAA). The cells were grown at $37^{\circ} \mathrm{C}$ in a humidified atmosphere with $5 \%$ $\mathrm{CO}_{2}$. For microirradiation experiments, cells obtained after trypsinisation of asynchronously growing stock cultures were seeded into $20 \mathrm{~cm}^{2}$ plastic Petri dishes. Cells were synchronized at early $\mathrm{S}$ phase, using a thymidine block (final concentration $2 \mathrm{mM} / \mathrm{ml}$ culture medium); $16-18 \mathrm{~h}$ later the block was removed. Eight hours later up to $40 \%$ of the cells arrived at mitosis $(2 \mathrm{~h}$ sampling time with colchicine $(0.2 \mu \mathrm{g} / \mathrm{ml})$. Cells were used for microirradiation either immediately after removal of the block or some $4-6 \mathrm{~h}$ later. Pulse-labelling experiments with $\left[{ }^{3} \mathrm{H}\right]$ thymidine $(0.1 \mu \mathrm{Ci} / \mathrm{ml}$ medium for $1 \mathrm{~h})$ followed by autoradiography were performed in this latter case and showed that most cells (90\%) were in $\mathbf{S}$ phase.

\section{Microirradiation procedure}

A continuous wave-coherent UV-beam with wavelength $257 \mathrm{~nm}$ [16] was focused with a quartz objective (Zeiss Ultrafluar $32 \times / 0.40 \mathrm{Ph}$ ), which was used simultaneously for microirradiation and observation of the cells in phase contrast. The adjustment of the beam was made in such a way that the focal plane of the beam and the object plane of the microscope coincided. Thus any cellular structure in focus of the microscope objective could be irradiated by the focal site of the beam. Its diameter was approx. $1 \mu \mathrm{m}$, as estimated from the smallest diameter of a fluorescent spot induced on the bottom of a Petri dish [15]. The 'effective' diameter of the irradiation field, however, was somewhat larger due to the divergence of the microbeam above and below its focal site and the effect of stray light produced when the beam passes a cellular structure. The cellular region selected for microirradiation was marked with a cross-hair located in the image plane of the objective. Horizontal movements of cells in irradiation chambers (see below) were realized by means of a special object stage (Gleittisch, Zeiss) which allows very fine adjustments. The irradiation time was controlled by a photographic shutter and varied between $\frac{1}{4}$ and $\frac{1}{30} \mathrm{sec}$. The UV-power incident at the cell surface was estimated to be approx. $7.5 \times 10^{-9} \mathrm{w}$. 


\section{Microirradiation of interphase nuclei}

Petri dishes were placed into a special irradiation chamber [21] and cells growing in 'experimental fields' marked by scalpel cuts were used for microirradiation. Non-irradiated cells adjacent to these fields served as controls. Cells were microirradiated at randomly selected sites of the nucleoplasm at room temperature. Petri dishes were kept out of the incubator for $30 \mathrm{~min}$ at maximum. After irradiation cells were either fixed immediately with methanol/acetic acid $(3: 1)$ or post-incubated with $2 \mathrm{mM}$ caffeine for 4-12 h. Colchicine was added $2 \mathrm{~h}$ before in situ chromosome preparation was performed [15]. For hypotonic treatment cells were incubated for $20 \mathrm{~min}$ in Hanks buffer diluted with aqua bidist. $(1: 20)$ plus $5 \%$ calf serum. Thereafter the hypotonic solution was gradually replaced by dropwise addition of fixative (methanol/acetic acid 3:1). In some experiments, interphase cells or metaphase spreads were microirradiated after fixation in order to exemplify the specifity and sensitivity of the immunocytochemical method.

\section{Microirradiation of chromatin at anaphase}

Cells were inoculated into Rose chambers [22] equipped with quartz glass windows. For experiments, the chambers were transferred to the irradiation microscope and kept there at $37^{\circ} \mathrm{C}$. Mitotic cells were localized and followed from metaphase to anaphase. The chromosome set on one side of a dividing cell in anaphase was microirradiated at one or two sites. After irradiation, the position of the cell within the Rose chamber was marked by a fine pencil and the chamber was transferred back to the incubator. One hour later the cells were fixed with methanol/acetic acid $(3: 1)$. In other experiments anaphase cells growing in Petri dishes were microirradiated as described above for interphase cells. Both types of experiments yielded identical results. However, recognition of structural details was improved by phase contrast observation of the cells in Rose chambers.

\section{Indirect immunofluorescence staining of $U V$-irradiated chromatin}

Details of the immunization procedure, purification and specifity of the rabbit antiserum raised against UV-irradiated DNA have been described elsewhere [23]. This antiserum has a high affinity for UV-irradiated DNA and possesses a low affinity for non-irradiated single-stranded DNA (ssDNA) [24]. Air-dried cells were stained 1 or 2 days after fixation. After rehydration for $30 \mathrm{~min}$ in PBS, the cells were incubated with undiluted antiserum for $2.5 \mathrm{~h}$ in a wet chamber. Cells were then washed for $30 \mathrm{~min}$ in PBS with three changes, incubated with fluorescein-isothiocyanate (FITC)-conjugated goat anti-rabbit IgG (dilution 1:30 in PBS; Nordic) for an additional $30 \mathrm{~min}$ at $37^{\circ} \mathrm{C}$, washed again three times with PBS and finally rinsed with bidistilled water for $10 \mathrm{~min}$. Thereafter cells were embedded under cover glass with Mowiol (Serva) or glycerin/PBS $(1: 1)$.

\section{DAPI staining}

In a number of experiments, cells were incubated with DAPI solution $(0.1 \mu \mathrm{g} / \mathrm{ml} \mathrm{PBS})$ for 3-6 min $\left(37^{\circ} \mathrm{C}\right)$ following the last PBS rinsing step of the immunofluorescence staining procedure. Then the cells were washed with bidistilled water and mounted in glycerin/PBS $(1: 1)$.

\section{Fluorescence microscopy}

Fluorescence microscopy and microphotography were performed with a Zeiss photomicroscope equipped with epifluorescence illumination. For observation the following filter combinations wcre used: LP 520, immunofluorescence alone; LP 420, DAPI staining alone; LP 470, simultaneous observation of DAPI and immunofluorescence.

\section{Autoradiography}

Cells contained in Petri dishes were covered with Ilford nuclear emulsion K2 and processed following standard procedures. Exposure time at $4^{\circ} \mathrm{C}$ was 2 weeks. Autoradiographs were stained with acetic orcein and metaphase plates were relocated and photographed. 

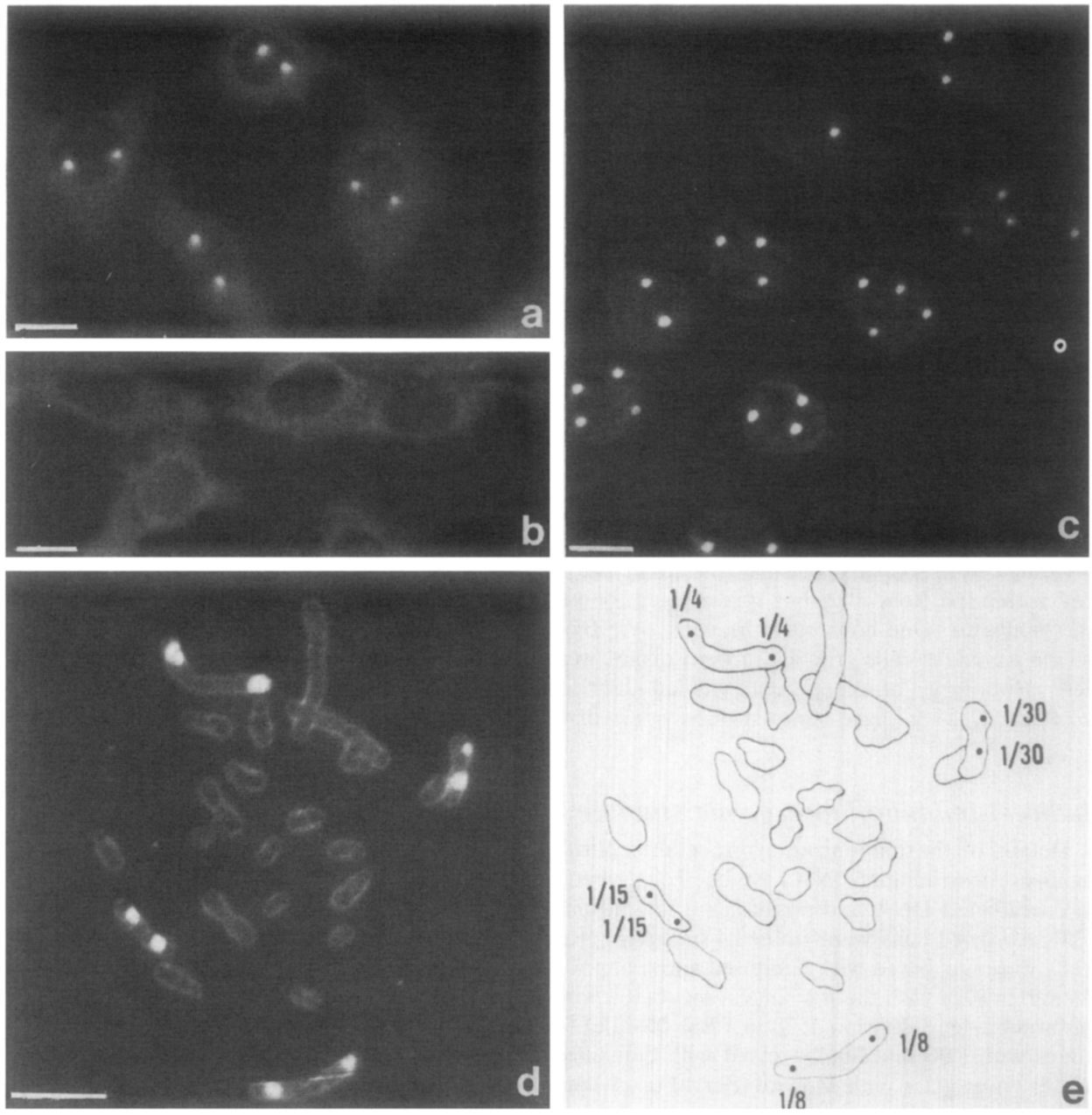

Fig. 1. (a) Nuclei of living Chinese hamster cells (M3-1 line) were microirradiated at two sites each (irradiation time $\frac{1}{8} \mathrm{sec}$ ) and fixed immediately thereafter. Microirradiated chromatin was identified by indirect immunofluorescence microscopy using antibodies raised against UV-irradiated DNA in rabbits. (Indirect immunofluorescence microscopy of $(b)$ non-irradiated cells (controls) grown in the neighbourhood of the microirradiated cells shown in $(a) ;(c)$ nuclei microirradiated after fixation at 1 , 2, 3 or 4 different sites ( $(\mathrm{g}$ sec); (d) an M3-1 metaphase spread. Fixed chromosomes were microirradiated at the sites marked by immunofluorescent label. The microphotograph does not reveal dosedependent differences (compare $e$ ) in the intensity of the fluorescent spots as noted in the original preparation. (e) Schematic diagram of the metaphase spread shown in $(d)$. The sites of microirradiation are indicated by black dots. The time of microirradiation varied between $\frac{1}{4}$ and $\frac{1}{30} \mathrm{sec}$. Bar, $10 \mu \mathrm{m}$.

\section{RESULTS}

Fig. 1 shows examples for the immunofluorescence labelling following laserUV-microirradiation of small parts of the nucleus in living (fig. $1 a$ ) or fixed (fig. $1 c$ ) interphase cells or of small parts of fixed metaphase chromosomes (fig. $1 d$, 
$e$ ). The number and the localization of the irradiation sites coincided with the number and the localization of immunofluorescent spots, e.g. microirradiation of $1,2,3$ or 4 sites of the nucleus resulted in a corresponding number of fluorescent spots at the preselected nuclear sites. The minimum diameter of the spots was approx. $1 \mu \mathrm{m}$ depending both on the exact adjustment of the focus of the microbeam within the nuclear target and the UV-incident dose. In the present experiments diameters of approx. $2 \mu \mathrm{m}$ were routinely achieved. These spots were not observed after microirradiation of the cytoplasm beside the nucleus or in non-irradiated control cells (fig. $1 b$ ).

Some $4-12 \mathrm{~h}$ after microirradiation, immunofluorescent labelling was still limited to one site of the nucleus. However, the intensity of the fluorescence appeared generally weaker. There was no indication that the size of labelled nuclear areas may increase largely during this post-incubation period (data not shown).

Fig. $1 d, e$ exemplifies the precision of aiming the microbeam to preselected sites of fixed metaphase chromosomes. The DNA photolesions induced by an incident UV-energy as low as $2.5 \times 10^{-10} \mathrm{~J}$ can clearly be visualized by antibody staining.

In figs 2 and 3, typical immunofluorescence distributions are presented, as observed in mitotic cells following a single microirradiation of a small part of the nucleus in $S$ phase and post-incubation for 4-12 h. Generally, caffeine ( $2 \mathrm{mM})$ was present during the post-incubation period. When the caffeine post-treatment was omitted, immunofluorescence was strongly decreased in the resulting mitotic specimens. This effect could only partly be compensated for by an increase of the UV-incident dose, since the yield of mitotic cells then became impractically low. No differences in the immunofluorescent labelling patterns were observed, whether the cells were microirradiated immediately after removal of the thymidine block or 4-6h later. In total, nuclei of some 17900 cells were microirradiated at a single site (except that nucleoli were generally avoided) and 253 mitotic cells with immunofluorescent labelling were obtained at the first post-irradiation mitosis.

During prophase ( $n=18$ ) (fig. 2), the immunofluorescence labelling was still restricted to one site as it was observed in interphase nuclei. This pattern was also found in the majority of metaphase cells with immunofluorescence labelling (190 out of 235) (fig. $3 a, b$ ). In 45 metaphase spreads several (up to five) clearly separated immunofluorescent spots were detectable. In general, however, these spots were still restricted to a rather limited part of the spread. Only in a few cases $(n=13)$ immunofluorescent chromosomes appeared distributed over a larger area (fig. $3 \mathrm{c}$ ). It should be noted that all metaphase spreads displaying strong immunofluorescence displayed also chromosome shattering of the labelled region, i.e. partial chromosome shattering, PCS. For a detailed description of this phenomenon, see $[7,25]$. Our result that labelled chromatin masses from several jointly microirradiated interphase chromosomes were still observed in close 

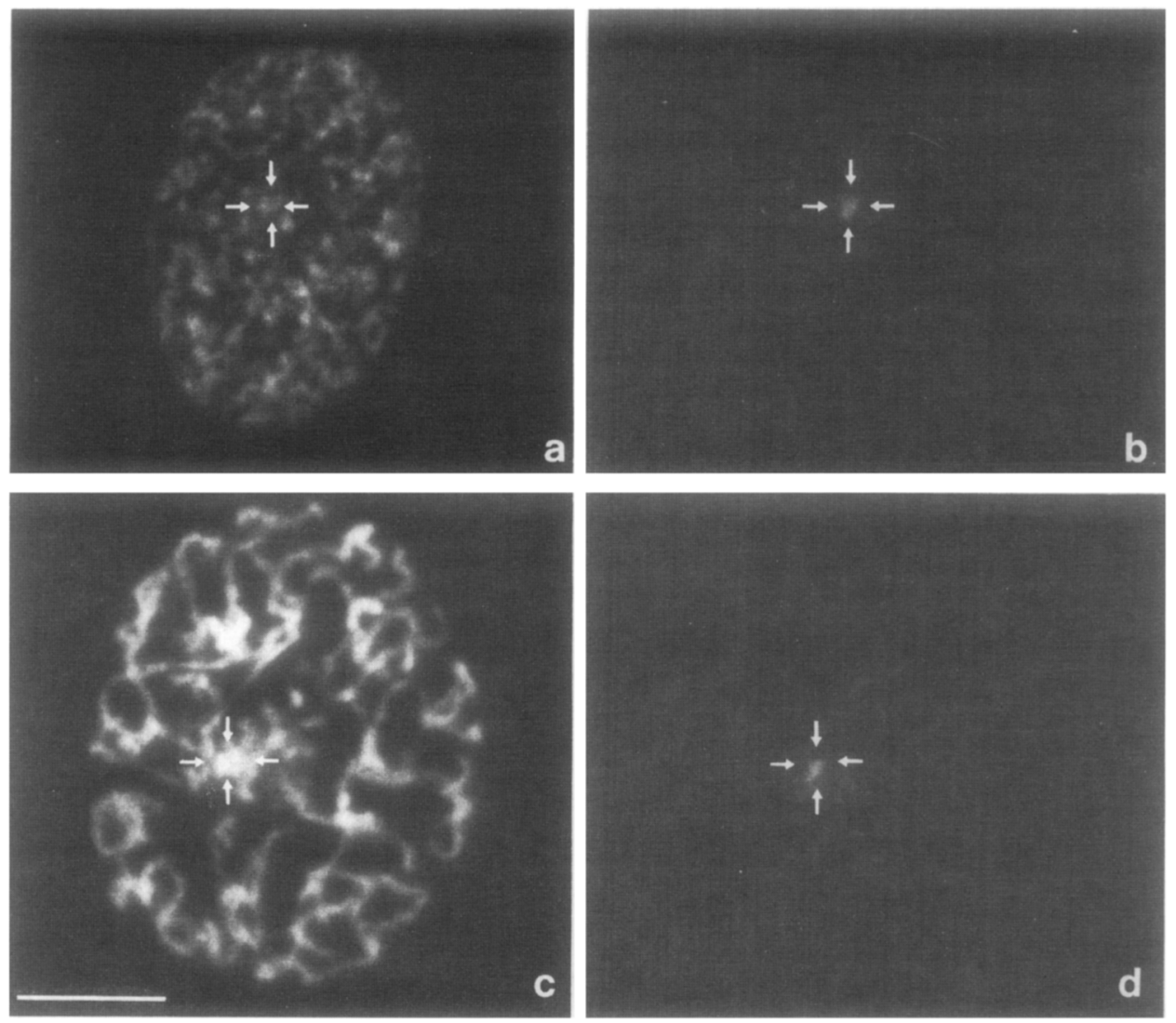

Fig. 2. M3-1 Chinese hamster cells were fixed in prophase after microirradiation of nuclei in $\mathrm{S}$ phase $\left(\frac{1}{30} \mathrm{sec}\right)$ and $4 \mathrm{~h}$ post-incubation in the presence of $2 \mathrm{mM}$ caffeine. $(a, c)$ Fluorescence microscopy of prophase chromosomes after DAPI staining; $(b, d)$ immunofluorescence microscopy of the same cells indicating the sites of UV-irradiated chromatin (compare arrows in $a, b$ and $c, d$, respectively). Bar, $10 \mu \mathrm{m}$.

neighbourship at metaphase (in spite of the use of colchicine and of a hypotonic shock during the chromosome preparation procedure) might not necessarily indicate the same close correlation between the interphase and metaphase positions of non-irradiated chromatin as well but possibly reflect an artefact of PCS. This problem is now under further investigation (H. Baumann \& T. Cremer, unpublished data).

Autoradiographs of metaphase spreads with immunofluorescent spots $(n=17)$ were obtained after pulse-labelling with $\left[{ }^{3} \mathrm{H}\right]$ thymidine $(0.1 \mu \mathrm{Ci} / \mathrm{ml}$ medium) for 1 $\mathrm{h}$ immediately after microirradiation, which was performed $4-6 \mathrm{~h}$ after removal of the thymidine block. They indicate that all of these 17 cells were in $\mathrm{S}$ phase at the time of microirradiation. Autoradiographic labelling patterns of 11 cells show incorporation of $\left[{ }^{3} \mathrm{H}\right]$ thymidine in all chromosomes of the complement (fig. $3 \mathrm{c}$ ), 

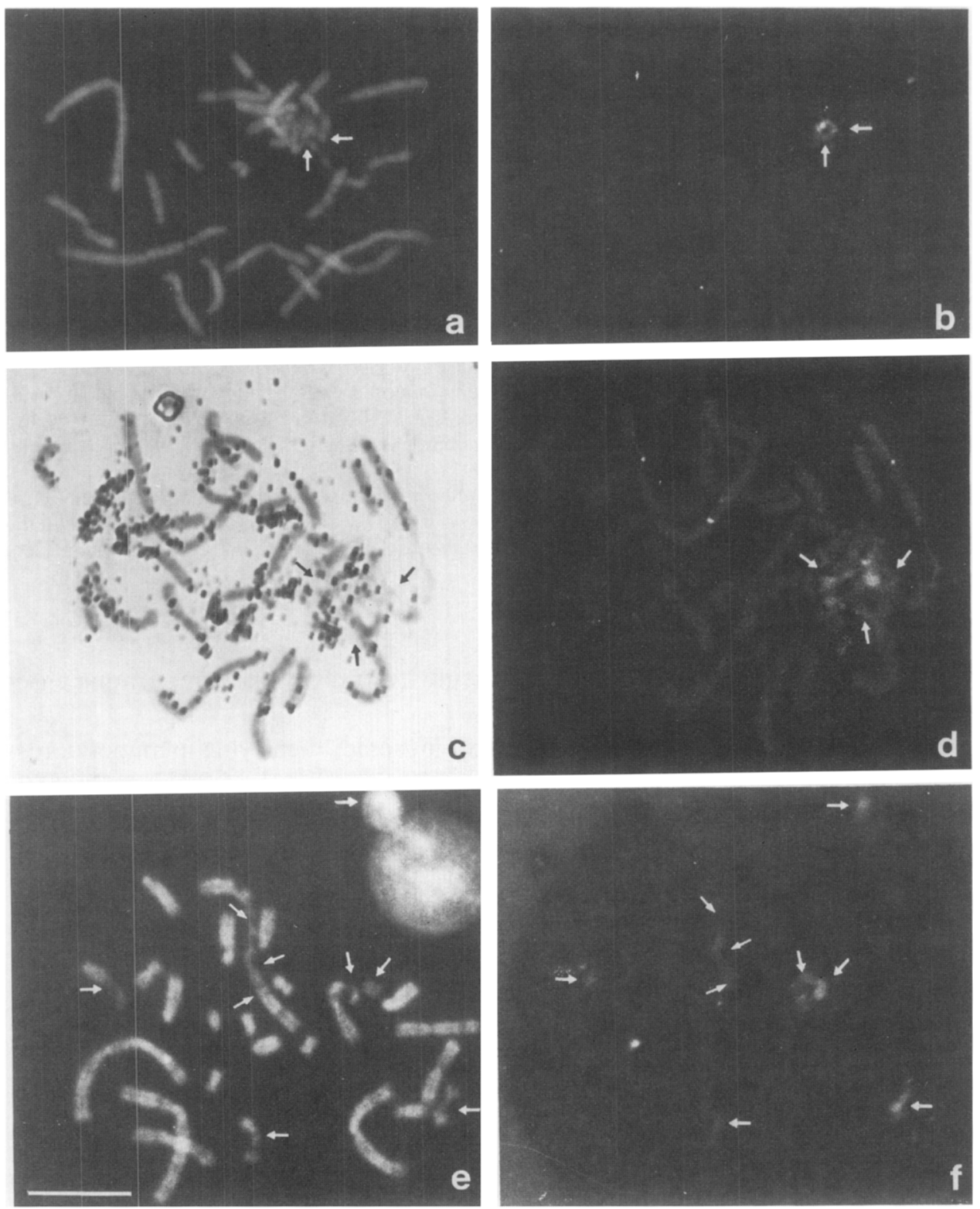

Fig. 3. Three metaphase spreads from M3-1 Chinese hamster cells obtained after microirradiation of nuclei in $S$ phase $\left(\frac{1}{30} \mathrm{sec}\right)$. Microirradiation was performed $6 \mathrm{~h}$ after release of the cells from a thymidine block. Thereafter the cells were post-incubated for another $4 \mathrm{~h}$ with $2 \mathrm{mM}$ caffeine. $(a, c, e)$ Metaphase spreads after staining of the chromosome complements with $(a, e)$ DAPI; or $(c)$ orcein. Immunofluorescence microscopy $(b, d, f)$ shows the sitcs of microirradiated chromatin in thesc spreads. Small arrows, corresponding sites of labelled chromatin. Note a micronucleus in an interphase cell in $(e)$, right upper corner, displaying immunofluorescence. The metaphase spread presented in $c, d$ was obtained from a cell pulse-labelled with $\left[{ }^{3} \mathrm{H}\right]$ thymidine for $1 \mathrm{~h}$ immediately after microirradiation. The autoradiograph $(c)$ shows silver grains over all chromosomes with grains more pronounced over late-replicating chromatin. Note that microirradiated chromosome material is shattered (partial chromosome shattering, PCS). In $(a, c)$ shattered chromosomes still appear clumped together, whereas in $(e)$ damage appears less pronounced in the affected chromosomes which are much more distributed over the metaphase spread. Bar, $10 \mu \mathrm{m}$. 

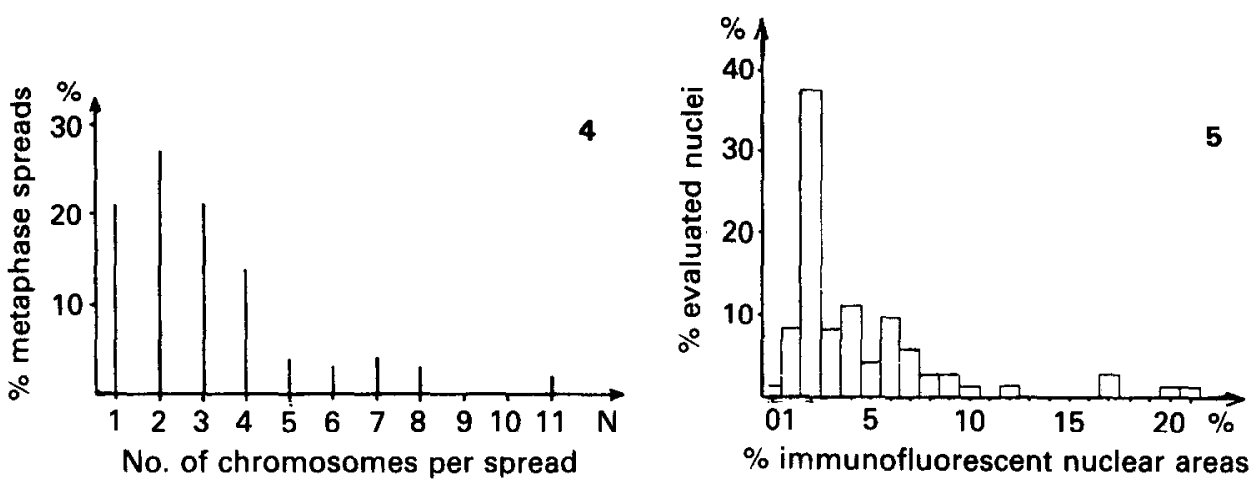

Fig. 4. Frequency distribution of the number of immunofluorescent labelled chromosomes in metaphase spreads obtained after microirradiation of nuclei of M3-1 cells in S phase (4-6 h after release from a thymidine block) and post-incubation for an additional $4-6 \mathrm{~h}$ in the presence of $2 \mathrm{mM}$ caffeine. Arithmetic mean, $\bar{x}=3.1 ; n=66$.

Fig. 5. Frequency distribution of the size of immunofluorescent nuclear areas of M3-1 cells obtained after microirradiation of nuclei at one site in $S$ phase and post-incubation of the cells for $4-6 \mathrm{~h}$ in the presence of $2 \mathrm{mM}$ caffeine. Class $0(0$ area 0.5$)$ contains one nucleus with $0.4 \%$ immunofluorescent area; arithmetic mean, $\bar{x}=45 \% ; n=72$.

whereas in six cases incorporation was mainly restricted to late-replicating chromatin.

Fig. 4 shows the apparent number of chromosomes displaying immunofluorescence in a population of 66 metaphase spreads suitable for further evaluation. Estimates were hampered by shattering (fragmentation/pulverization) of microirradiated chromosomes. The frequency distribution of immunofluorescent labelled chromosomes shows a maximum of two labelled chromosomes per spread and an arithmetic mean of 3.1, i.e. parts of these chromosomes were situated in the microirradiated nuclear segment. In a few cases only, a considerably larger number of labelled chromosomes (up to 11) was estimated. These cases may partly stem from cells in which a somewhat larger nuclear area was microirradiated (compare fig. 5). In addition, higher numbers were estimated in cases where chromosomes were heavily overlapping around the fluorescent site of the spread. Thus, the numbers of labelled chromosomes in these cases represent a maximum estimate derived from counts of surrounding intact chromosomes.

Fig. 5 shows the frequency distribution of the immunofluorescent nuclear area as a percentage of the total nuclear area from 72 randomly selected interphase nuclei. These nuclei showed a close neighbourship to one of the 66 metaphase spreads used for the evaluation represented above (fig. 4). Most nuclei showed a labelled area between 1 and $10 \%$ of their total area with a maximum at $2 \%$ and an arithmetic mean of $4.5 \%$. Only occasional cells showed a labelled area up to $20 \%$. These occasional cells may have been microirradiated slightly out of focus and thus been exposed to the divergent part of the microbeam above or below its focal site (see Material and Methods, "Microirradiation procedure"). 
Fig. 6 shows the results of microirradiation of chromosomes at anaphase. In phase contrast the two chromosome sets of a living cell were easily discriminated at late anaphase (fig. $6 a$ ), the left set was microirradiated at two sites $\left(\frac{1}{8} \mathrm{sec}\right)$. Phase-contrast observation did not reveal any apparently disturbing effect on the subsequent formation of the two daughter cells. After fixation (performed $1 \mathrm{~h}$ later) both nuclei appeared to have a normal shape (fig. $6 \mathrm{~b}$ ). Immunofluorescent staining (fig. $6 c$ ) revealed the position of the microirradiated chromatin enclosed in the left nucleus. Two small nuclear areas were distinctly stained. The right nucleus did not show any immunofluorescence (compare fig. $6 c$ with the scheme in fig. $6 e, f$ ). Fig. $6 g$ shows the result of another experiment. It was carried out in the same manner as the first experiment, except that only one site of the left chromosome set was irradiated. Fig. $6 e$ shows the two daughter nuclei after fixation $1 \mathrm{~h}$ later. Immunofluorescence staining revealed one small fluorescent area in the nucleus containing the microirradiated chromosome set (compare fig. $6 f$ with the scheme in fig. $6 \mathrm{~g}$ ). Note that in both experiments the immunofluorescent areas (fig. $6 c, f$ ) appear generally more extended and more diffuse at the edges than the immunofluorescent spots observed immediately after microirradiation of interphase nuclei (fig. $1 a, c$ ). This might result from movements and decondensation processes of the microirradiated chromosome segments during formation of the G1 nucleus. However, precise focusing of the microbeam is impeded in rounded anaphase cells and a technical artefact due to an increased amount of straylight may also account for the diffuse edges of the spots. In total, 28 anaphase cells were microirradiated. In 18 cases immunofluorescence was observed. In seven cases one of the two chromosome sets was microirradiated at one site and in eleven cases at two sites. In all cases, the labelled daughter cell nucleus was the one which had received the microirradiated chromosome set, the number of fluorescent areas corresponding with the number of sites microirradiated at anaphase. Furthermore, without exception the total immunofluorescent area comprised only a minor fraction of the entire nuclear area.

\section{DISCUSSION}

UV-microirradiation experiments offer a direct approach to investigate the spatial organization of chromosomes in interphase. The experimental rationale of these experiments is to microirradiate a small amount of chromatin during interphase or mitosis and to examine how such a probe of chromatin is distributed during subsequent stages of the cell cycle. Apparently, conclusions concerning the spatial arrangement of the interphase chromosomes can be drawn from such data [12]. To detect the chromatin modified by UV microirradiation, different approaches may be used. Previously, unscheduled DNA synthesis (UDS) was used to identify the irradiated chromatin following UV microirradiation of interphase cells in G1 phase [12, 15]. These studies have shown that the interphase chromosomes in G1 nuclei of euploid Chinese hamster cells, synchronized by 

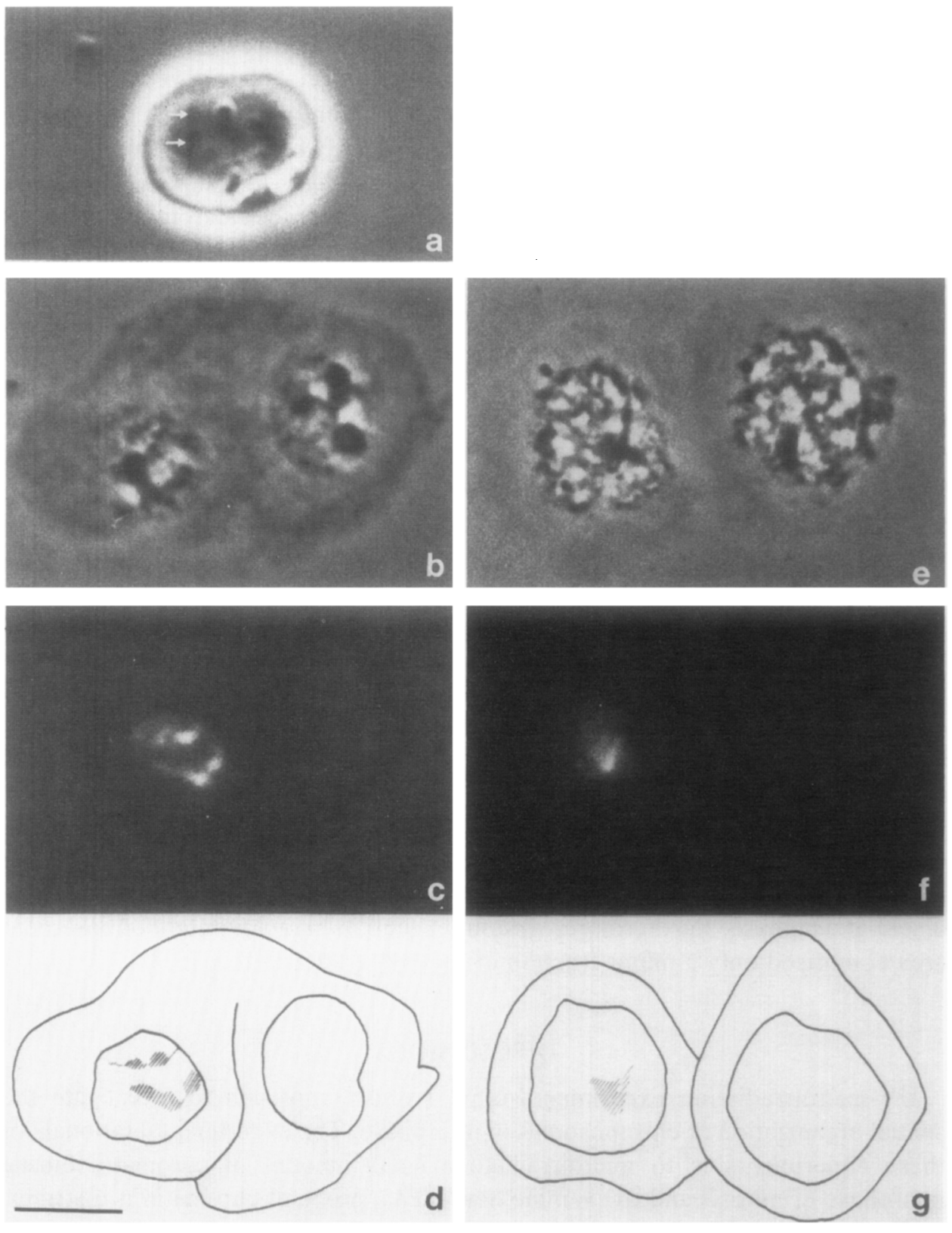

Fig. 6. Laser-UV-microirradiation of chromosomes at anaphase. In one experiment $(a-d)$ the left chromosome set was microirradiated $\left(\frac{1}{8} \mathrm{sec}\right)$ at two sites $(a$, arrows) and phase-contrast microphotography of the living cell was performed immediately thereafter. One hour later the resulting daughter nuclei were fixed ( $b$, phase-contrast microphotography of the unstained cells). Immunofluorescence microscopy of the nuclei revealed two distinct immunofluorescent regions in the left nucleus; compare scheme $(d)$. In another experiment $(e-g)$ the left chromosome set was microirradiated at one site (not shown). The two daughter nuclei were fixed $1 \mathrm{~h}$ post-irradiation $(e)$. Immunofluorescence microscopy showed one labelled region on the left nucleus which had received the microirradiated chromatin $(f)$; compare scheme $(g)$. Bar, $10 \mu \mathrm{m}$. 
serum starvation, are organized in distinct 'territories' or domains. In addition, premature chromosome condensation in G1 and G2 nuclei of the same cells supported the type of interphase chromosome orientation first proposed by Rabl [12]. Direct evidence for a territorial organization of the interphase chromosomes was lacking so far for nuclei in $\mathbf{S}$ phase. Obviously, in this case pulse-labelling with $\left[{ }^{3} \mathrm{H}\right]$ thymidine cannot be used for detection of UDS in microirradiated chromatin.

In this study chromatin microirradiated at a given nuclear site in $\mathrm{S}$ phase has been visualized in the subsequent stages of the cell cycle, including prophase and metaphase, by immunofluorescence staining technique using antibodies specific for the detection of UV-irradiated DNA. An average of three chromosomes per metaphase plate have shown immunofluorescent labelling. When compared with our previous data on the arrangement of interphase chromosomes in G1 [12, 15], this result indicates that individual chromosomes during $S$ phase do not become extended over a much larger part of the nucleus but still occupy relatively small territories or domains. Interestingly, in 14 out of 66 metaphase spreads (fig. 5) only one chromosome has displayed significant immunofluorescence. This could mean that the nuclear domains of these chromosomes are extended between the upper and lower part of the nuclear envelope of the flatly shaped M3-1 nuclei. If the domains of two (or more) chromosomes would necessarily overlap, we could except a minimum of two labelled chromosomes even in cases where the nuclear area exposed to microirradiation was only $1 \%$ or less of the total nuclear area. Alternatively, we have to consider the possibility that the immunofluorescence signal on some microirradiated neighbouring chromosome territories was too weak to be detected in these cases.

In other experiments, chromosomes were microirradiated in anaphase, and the microirradiated chromatin was detected in the resulting G1 nucleus. As expected for a territorial organization only a minor fraction of the nucleus has been labelled. Similar results have previously been obtained by UV microirradiation of pig embryo kidney cells in anaphase and incubation in medium containing $\left[{ }^{3} \mathrm{H}\right]$ thymidine followed by autoradiography [26].

The term 'chromosome territory' or 'domain' implies that the individual chromosome occupies a distinct and limited segment of the interphase nucleus. Polytene nuclei found in certain tissues of Drosophila and other Diptera provide well known examples for such an organization pattern [27]. This concept still gives place for an enormous variability in the actual arrangement of single interphase chromosomes. However, it restricts the possibilities by which the chromatin fibres of which each individual chromosome is formed can be distributed within the nucleus. Evidence has been described that the DNA of individual chromosomes is organized both in interphase and metaphase chromosomes in loops of the same order of magnitude, e.g. 10-180 kilobase pair ( $\mathrm{kbp})$ length (average number $53 \mathrm{kbp}$ ) for mouse interphase DNA and $42 \mathrm{kbp}$ for HeLa metaphase chromosomes [28-30]. We feel a loop model to be especially attractive 


\section{Hens et al.}

but the limiting conditions set by the results of our present experiments are valid for any model of the folding and distribution of chromatin fibres in the interphase nucleus. The fluorescent labelling patterns which we have found suggest that possible loops of the chromatin fibre are generally rather short during the entire cell cycle, as compared with the dimensions of the nucleus. Based on clectron microscopic evidence it has recently been suggested that the interphase nucleus "could ... contain smaller domains which represent the DNA complement of single mitotic chromosomes" [30]. Thus the concept of a territorial organization now seems to be supported by independent experimental observations.

Presently, litte information is available concerning the ultrastructure of the boundaries between adjacent interphase chromosome territories. Some intermingling of short loops from neighbouring chromosomes would be consistent with our results. Intermingling of long loops of chromatin fibres invading the microirradiated nuclear area from distant chromosome territories does not appear to be a major event, since such a type of intermingling should have led to metaphase spreads exhibiting fluorescent label scattered over many chromosomes rather than concentrated over a few.

The combination of the UV-microirradiation technique with immunocytochemical methods offers a powerful tool in studies of the question of a random or non-random arrangement of interphase chromosomes [7, 12]. In addition, it has been valuable for studies of the dynamic aspects of chromosome arrangement during subsequent stages of the cell cycle, such as interphase-mitosis-interphase transition (H. Baumann, K. Nakanishi \& T. Cremer, unpublished data).

As reported elsewhere [25], UV-microirradiation of Chinese hamster nuclei in G1 or S phase plus caffeine post-treatment (1-2 $\mathrm{mM}$ ) results in two major types of chromosome damage at the first post-irradiation mitosis, namely partial (PCS) and generalized (GCS) chromosome shattering. In the latter case shattering affects all the chromosomes of a cell. However, even in the case of GCS we were able to demonstrate, by immunofluorescent and UDS labelling methods, that microirradiated chromatin comprises only a small fraction of the whole chromosome complement [18]. This result supports our hypothesis that GCS results largely from an indirect effect of UV-microirradiation and occurs both in irradiated and non-irradiated chromosomes [25, 31]. Under the conditions of our present experiments GCS was a very rare event, probably due to an antagonistic effect of the thymidine block used for synchronization [32].

Finally, the influence of the caffeine post-treatment of microirradiated cells on the intensity of the immunofluorescence staining needs further elucidation. The reason for this effect is presently unknown. In mammalian cells caffeine does not interfere with the removal of DNA lesions by excision repair [33, 34]. A larger number of DNA photolesions in microirradiated chromatin of caffeine-posttreated cells, as compared with non-treated cells, therefore does not suffice as an explanation for the decreased intensity of immunofluorescence in the latter. However, it should be noted that the antibodies used for the detection of UV- 
irradiated DNA do not detect DNA photolesions like pyrimidine dimers per se but rather small conformational changes of DNA at the lesion-bearing sites. Caffeine may interfere with processes which influence the structure or the accessibility of these antigenic sites.

We thank the Deutsche Forschungsgemeinschaft for financial support and Deutscher Akademischer Austauschdienst for a post-graduate scholarship (L. H.). The technical assistance of Miss Nadja Bulbuc is gratefully acknowledged. We are indebted to Drs $\mathbf{M}$. Kirsch-Volders, T. M. Schroeder, F. Vogel and C. Susanne for their continued interest and encouragement.

\section{REFERENCES}

1. Bennett, M D, Genome evolution (ed G A Dover \& R B Flavell) p. 239. Academic Press, New York, London (1982).

2. Hens, L, Kirsch-Volders, M, Verschaeve, L \& Susanne, C, Hum genet 60 (1982) 249.

3. Comings, D E, Hum genet 53 (1980) 131.

4. Vogel, F \& Schroeder, T M, Hum genet 25 (1974) 265.

5. Avivi, L \& Feldmann, M, Hum genet 55 (1980) 281.

6. Hager, H D, Schroeder-Kurth, T M \& Vogel, F, Hum genet 61 (1982) 342.

7. Cremer, T, Cremer, C, Schneider, T, Baumann, H, Hens, L \& Kirsch-Volders, M, Hum genet 62 (1982) 201.

8. Rabl, C, Morphologisches Jahrbuch 10 (1885) 214.

9. Boveri, Th, Jenaische Zeitschrift für Naturwissenschaft 22 (1888) 687.

10. Boveri, Th, Archiv für Zellforschung 3 (1909) 181.

11. Sperling, K \& Luedtke, E K, Chromosoma 83 (1981) 541.

12. Cremer, T, Cremer, C, Baumann, H, Luedtke, E K, Sperling, K, Teuber, V \& Zorn, C, Hum genet 60 (1982) 46.

13. Stack, S M, Brown, D B \& Dewey, W C, J cell sci 26 (1977) 281.

14. Hancock, R, Biol cell 46 (1982) 105.

15. Zorn, C, Cremer, C, Cremer, T \& Zimmer, J, Exp cell res 124 (1979) 111.

16. Cremer, C, Zorn, C \& Cremer, T, Microsc acta 75 (1974) 331.

17. Cremer, C, Cremer, T, Fukuda, M \& Nakanishi, K, Hum genet 54 (1980) 107.

18. Cremer, C, Cremer, T, Hens, L, Baumann, H, Cornelis, J J \& Nakanishi, K, Mutat res 107 (1983) 465.

19. Gray, J W, Carrano, A V, Steinmetz, L L, van Dilla, M A, Moore II, D H, Mayall, B H \& Mendelsohn, M L, Proc natl acad sci US 72 (1975) 1231.

20. Cremer, C \& Gray, J W, Cytometry 3 (1983) 282.

21. Cremer, C, Cremer, T, Zorn, C \& Schoeller, L, Rad res 66 (1976) 106.

22. Berns, M W, Cold Spring Harbor symp quant biol 38 (1974) 165.

23. Cornelis, J J \& Errera, M, DNA repair, a laboratory manual of research procedures (ed E C Friedberg \& P C Hanawalt) vol. 1, part A, p. 31. Marcel Dekker, New York, Basle (1980).

24. Cornelis, J J, Nucleic acid res 5 (1978) 4273.

25. Cremer, C, Cremer, T, Zorn, C \& Zimmer, J, Mutat res 84 (1981) 331.

26. Sakharov, V N, Voronkova, L N, Pyruzyan, L A \& Lomakina, L Y, Nature 260 (1976) 784.

27. Sedat, J \& Manuelidis, L, Cold Spring Harbor symp quant biol 42 (1978) 331.

28. Laemmli, U K, Cheng, S M, Adolph, K W, Paulson, J R, Brown, J A \& Baumbach, W R, Cold Spring Harbor symp quant biol 42 (1978) 351.

29. Earnshaw, W C \& Laemmli, U K, J cell biol 96 (1983) 84.

30. Hancock, R \& Hughes, M E, Biol cell 44 (1982) 201.

31. Cremer, T, Peterson, S P, Cremer, C \& Berns, M W, Rad res 85 (1981) 529.

32. Cremer, C, Cremer, T \& Simickova, M, Environ mutagen 2 (1980) 339.

33. Regan, J, Trosko, J E \& Carrier, W L, Biophys j 8 (1968) 319.

34. Trosko, J E \& Chu, E H Y, Chem biol interact 6 (1973) 317.

Received March 20, 1983

Revised version received April 28, 1983 